\title{
Prognostic value of intraoperative pleural lavage cytology for non-small cell lung cancer: The influence of positive pleural lavage cytology results on $T$ classification
}

\author{
Kotaro Kameyama, MD, ${ }^{\mathrm{a}}$ Norihito Okumura, MD, ${ }^{\mathrm{a}}$ Etsuo Miyaoka, $\mathrm{PhD},{ }^{\mathrm{b}}$ Hisao Asamura, MD, \\ Ichiro Yoshino, MD, ${ }^{\mathrm{d}}$ Hirohito Tada, MD, ${ }^{\mathrm{e}}$ Yoshitaka Fujii, $\mathrm{MD},{ }^{\mathrm{f}}$ Yoichi Nakanishi, MD, ${ }^{\mathrm{g}}$ \\ Kenji Eguchi, MD, ${ }^{\mathrm{h}}$ Masaki Mori, MD, ${ }^{\mathrm{i}}$ Hideo Kobayashi, MD, ${ }^{\mathrm{j}}$ Noriyoshi Sawabata, MD, ${ }^{\mathrm{k}}$ \\ Meinoshin Okumura, MD, ${ }^{\mathrm{k}}$ and Kohei Yokoi, MD, for the Japanese Joint Committee of \\ Lung Cancer Registry
}

Objective: Although positive pleural lavage cytology (PLC) has been demonstrated to be closely associated with a poor prognosis for patients with lung cancer, it has not been incorporated into the TNM staging system of the Union for International Cancer Control. The aim of our study was to retrospectively examine the clinical significance of PLC status and illustrate the recommendations of the International Pleural Lavage Cytology Collaborators (IPLCC) in a large national database.

Methods: The Japanese Joint Committee of Lung Cancer Registry database included 11,073 patients with non-small cell lung cancer who underwent resections in 2004. We extracted the clinicopathologic data for 4171 patients $(37.3 \%)$ who underwent PLC. These patients were staged according to the seventh edition of the Union for International Cancer Control TNM classification and by recommendations of the IPLCC, in which $\mathrm{T}$ was singly upgraded up to a maximum of T4 for those who were PLC-positive. Prognoses based on these 2 systems were compared.

\begin{abstract}
Results: A total of 217 patients (5.2\%) were PLC-positive, which was significantly associated with a higher incidence of adenocarcinoma and advanced disease. The 5-year survival for patients with positive and negative PLC results were $44.5 \%$ and $72.8 \%$, respectively, and this difference in survival was statistically significant $(P<.001)$. Multivariate analysis showed that positive PLC status was an independent factor for a poor prognosis (hazard ratio, $1.57 ; P<.001$ ). Significant differences in survival were also found between patients with positive and negative PLC results in the same T categories and stages, including T2a, T3, stage IB, and stage IIIA. The IPLCC recommendations adjusted the prognostic differences in all $\mathrm{T}$ categories and stages. The significant difference in survival disappeared between the 2 groups in all $\mathrm{T}$ categories and stages.
\end{abstract}

Conclusions: Our results indicate that a $\mathrm{T}$ category upgrade is prognostically adequate for patients who are PLC-positive. (J Thorac Cardiovasc Surg 2014;148:2659-64)

\footnotetext{
From the Department of Thoracic Surgery, ${ }^{a}$ Kurashiki Central Hospital, Kurashiki, Japan; Department of Mathematics, ${ }^{\text {b }}$ Science University of Tokyo, Tokyo, Japan; Division of Thoracic Surgery, ${ }^{\mathrm{c}}$ National Cancer Center Hospital, Tokyo, Japan; Department of General Thoracic Surgery, ${ }^{\mathrm{d}}$ Chiba University Graduate School of Medicine, Chiba, Japan; Division of General Thoracic Surgery, ${ }^{\mathrm{e}}$ Osaka City General Hospital, Osaka, Japan; Department of Oncology, Immunology, and Surgery, Nagoya City University Graduate School of Medical Science and Medical School, Nagoya, Japan; Research Institute for Diseases of the Chest, ${ }^{g}$ Graduate School of Medical Sciences, Kyushu University, Fukuoka, Japan; Department of Medical Oncology, ${ }^{\mathrm{h}}$ Teikyo University School of Medicine, Tokyo, Japan; Department of Pulmonary Medicine, ${ }^{i}$ Sapporo-Kosei General Hospital, Hokkaido, Japan; Division of Respiratory Disease, ${ }^{\mathrm{j}}$ National Defense Medical College, Saitama, Japan; Department of General Thoracic Surgery, ${ }^{\mathrm{k}}$ Osaka University Graduate School of Medicine, Osaka, Japan; and Department of Thoracic Surgery, ${ }^{1}$ Nagoya University Graduate School of Medicine, Nagoya, Japan.

Disclosures: Yoichi Nakanishi reports consulting fees from Pfizer, Chugai, and Boehringer Ingelheim Japan. All other authors have nothing to disclose with regard to commercial support.

Received for publication Nov 13, 2013; revisions received June 23, 2014; accepted for publication July 13, 2014; available ahead of print Aug 28, 2014.

Address for reprints: Kotaro Kameyama, MD, Department of Thoracic Surgery,

Kurashiki Central Hospital, 1-1-1 Miwa, Kurashiki, Okayama 710-8602, Japan (E-mail: kk8724@kchnet.or.jp).

$0022-5223 / \$ 36.00$

Copyright (c) 2014 by The American Association for Thoracic Surgery

http://dx.doi.org/10.1016/j.jtcvs.2014.07.090
}

See related commentary on pages 2665-6.

For surgical cases of primary lung cancer, pleural lavage cytology (PLC) is a simple, easily done technique that provides a cytodiagnosis at the time of thoracotomy to evaluate subclinical pleural dissemination of cancer cells without pleural dissemination or pleural effusion. After a PLC result was first reported by Eagan and colleagues $^{1}$ in 1984 , numerous studies have shown that PLC status is a prognostic factor for primary lung cancer. $^{2-22}$ In general, the frequency of positive results is $<10 \%$ of patients who underwent PLC in the larger published series. In previous multiinstitution studies, a positive PLC result was suggested to be an independent prognostic factor and a predictor of tumor recurrence. ${ }^{22-26}$

However, PLC findings were not incorporated in the TNM Classification of Malignant Tumours. ${ }^{27,28}$ In 2010, the 


\section{Abbreviations and Acronyms \\ IPLCC = International Pleural Lavage Cytology Collaborators \\ NSCLC $=$ non-small cell lung cancer \\ PLC = pleural lavage cytology \\ UICC = Union for International Cancer Control}

International Pleural Lavage Cytology Collaborators (IPLCC) reported the results of a meta-analysis and recommended that a single increase in the $\mathrm{T}$ category up to a maximum of $\mathrm{T} 4$ be assigned to patients with positive PLC results. ${ }^{24}$

The aim of our study was to retrospectively examine the clinical significance of PLC status and to illustrate the recommendations of the IPLCC. We used a large national database that were compiled by the Japanese Joint Committee of Lung Cancer Registry. ${ }^{29,30}$

\section{PATIENTS AND METHODS}

In 2010, the Japanese Joint Committee of Lung Cancer Registry performed a nationwide retrospective registry study on the prognosis and clinicopathologic profiles of resected lung neoplasms in Japan. ${ }^{29,30}$ Only primary lung neoplasms that had been resected in 2004 at certified teaching hospitals in Japan were considered for the registry, which provided a follow-up period of at least 5 years. The committee received the registries of 11,663 patients from 253 teaching hospitals.

This registry followed the ethical guidelines for epidemiologic studies published jointly by the Japan Ministry of Science, Culture, and Education and the Japan Ministry of Health, Labor, and Welfare published June 17, 2002, which were revised August 16, 2007. In addition, it was approved by the institutional review board of Osaka University Medical Hospital, where the registry office is located, after discussions were published August 13, 2009 (approval No. 09124).

The patients in this study were 4171 patients who underwent PLC from among 11,073 patients with non-small cell lung cancer (NSCLC) (37.3\%). Cases involving malignant pleural effusion were excluded. There were 2524 men and 1647 women. Adenocarcinoma was detected in 2977 patients, squamous cell carcinoma in 881 patients, large cell carcinoma in 149 patients, adenosquamous carcinoma in 81 patients, and other histologic types in 83 patients. The seventh edition of the Union for International Cancer Control (UICC) TNM classification system was used for the evaluations of TNM staging. ${ }^{28}$ There were 1694 patients in stage IA, 1009 patients in stage IB, 378 patients in stage IIA, 262 patients in stage IIB, 703 patients in stage IIIA, 38 patients in stage IIIB, and 87 patients in stage IV. In our study, the PLC technique used had not been standardized. Induction therapy was performed in 199 patients (chemotherapy in 118 patients, radiation therapy in 6 patients, and chemoradiotherapy in 75 patients). Adjuvant chemotherapy was administered to 977 patients. These menus were not uniform.

To correct the prognoses according to the pathologic stages of patients with positive PLC results to patients with negative PLC results, pathologic stages were reevaluated based on the recommendations of the IPLCC: a single increase in the $\mathrm{p}-\mathrm{T}$ category up to a maximum of $\mathrm{T} 4$ was assigned to patients with a positive PLC result (upstage). ${ }^{24}$ Single increases in the $\mathrm{T}$ category upstaged T1a to T1b, T1b to T2a, T2a to T2b, T2b to T3, and T3 to T4. Pathologic stages were rearranged according to the upstaged $\mathrm{T}$ categories.

Categorical data are presented as frequency and continuous data are presented as means with standard deviations. Comparisons of categorical data between the 2 groups were made using $\chi^{2}$ tests or Fisher exact tests where appropriate and continuous data were compared using 2-tailed $t$ test. The survival time was measured from the date of surgery to the death date or the last follow-up date. The survival curves were estimated by using the Kaplan-Meier method. Differences in survival were assessed by the log-rank test. Multivariate analyses of prognostic factors were carried out using Cox proportional hazard regression models. A $P$ value $<.05$ was considered to be significant.

\section{RESULTS}

Among 4171 patients who underwent PLC, 217 patients $(5.2 \%)$ had positive PLC results (Table 1). Patients with positive PLC results had larger tumors $(P<.0001)$ and more frequently adenocarcinoma in the histology $(P<.0001)$, advanced stage $(P<.0001)$, and pleural invasion $(P<.0001)$ in comparison with those who were PLC-negative.

Sixty-five percent of patients with positive PLC and $29.2 \%$ of PLC-negative patients developed recurrence within 5 years after surgery $(P<.0001)$. The 5 -year survival was $44.5 \%$ for patients with positive PLC results and was $72.8 \%$ for patients with negative PLC results $(P<.0001)$ (Figure 1). By multivariate analysis using a Cox proportional hazard regression model, PLC status (hazard ratio, 1.57; 95\% confidence interval, 1.276-1.919; $P<.0001$ ) and other clinical factors (ie, gender, age, $\mathrm{T}$ category, $\mathrm{N}$ category, $\mathrm{M}$ category, and tumor size) were independent prognostic factors (Table 2).

Comparisons of the survival between patients with positive and negative PLC results according to T categories revealed significant differences in T2a $(P<.0001)$ and T3 $(P=.0184)$ (Figure 2 and Table 3$)$. In addition, comparisons of the survival between patients with positive and negative PLC results according to pathologic stages revealed significant differences in stage IB $(P=.0062)$ and stage IIIA $(P=.0115)$ (Table 3$)$. Based on the recommendations of the IPLCC, if a single increase in the $\mathrm{T}$ category up to a maximum of $\mathrm{T} 4$ was assigned to a patient with a positive PLC result, the significant difference in survival disappeared between the 2 groups in all $\mathrm{T}$ categories and stages. (Figure 3 and Table 4).

\section{DISCUSSION}

Body cavity fluid cytology is a simple, easily done technique that provides an intraoperative cytodiagnostic evaluation of latent dissemination of cancer cells. ${ }^{31}$ In surgical cases of abdominal malignant tumors, PLC status is an independent prognostic factor, as reflected in the UICC TNM classification for gastric, uterine, ovarian, and fallopian tube cancers. ${ }^{28}$ PLC status is directly involved in the treatment strategy. However, PLC findings were not incorporated in the seventh edition of the UICC TNM staging system. ${ }^{28,32}$ It is not known to what extent the noninclusion of PLC results affects treatment strategies.

In this study, $5.2 \%$ of patients who underwent PLC had positive results. When these patients were examined by $\mathrm{T}$, 
TABLE 1. Clinicopathologic characteristics according to pleural lavage cytology (PLC) results

\begin{tabular}{|c|c|c|c|}
\hline Characteristic & Positive PLC & Negative PLC & $P$ value \\
\hline Age (y) & $66.2 \pm 9.9$ & $66.3 \pm 9.8$ & .9040 \\
\hline Gender & & & .0640 \\
\hline Male & 118 & 2406 & \\
\hline Female & 99 & 1548 & \\
\hline Histologic type & & & $<.0001$ \\
\hline Adenocarcinoma & 193 & 2784 & \\
\hline Squamous cell carcinoma & 19 & 862 & \\
\hline Others & 5 & 308 & \\
\hline Surgical procedure & & & .0460 \\
\hline Pneumonectomy & 9 & 121 & \\
\hline Lobectomy & 177 & 3239 & \\
\hline Segmentectomy & 14 & 321 & \\
\hline Wedge resection & 10 & 234 & \\
\hline Others & 7 & 38 & \\
\hline $\mathrm{T}$ category & & & $<.0001$ \\
\hline T1a & 14 & 1147 & \\
\hline $\mathrm{T} 1 \mathrm{~b}$ & 12 & 771 & \\
\hline $\mathrm{T} 2 \mathrm{a}$ & 138 & 1390 & \\
\hline $\mathrm{T} 2 \mathrm{~b}$ & 9 & 186 & \\
\hline $\mathrm{T} 3$ & 35 & 394 & \\
\hline $\mathrm{T} 4$ & 9 & 66 & \\
\hline $\mathrm{N}$ category & & & $<.0001$ \\
\hline No & 109 & 3040 & \\
\hline N1 & 26 & 318 & \\
\hline $\mathrm{N} 2$ & 81 & 584 & \\
\hline N3 & 1 & 12 & \\
\hline M category & & & $<.0001$ \\
\hline M0 & 187 & 3886 & \\
\hline M1a & 27 & 30 & \\
\hline M1b & 3 & 38 & \\
\hline Pathologic stage & & & $<.0001$ \\
\hline IA & 15 & 1679 & \\
\hline IB & 60 & 949 & \\
\hline IIA & 23 & 355 & \\
\hline IIB & 12 & 250 & \\
\hline IIIA & 74 & 629 & \\
\hline IIIB & 4 & 34 & \\
\hline IV & 29 & 58 & \\
\hline Tumor size $(\mathrm{cm})$ & $3.40 \pm 1.63$ & $2.99 \pm 1.80$ & \\
\hline Pleural factor & & & $<.0001$ \\
\hline pl 0 & 47 & 2759 & \\
\hline pl 1 & 56 & 669 & \\
\hline pl 2 & 85 & 229 & \\
\hline pl 3 & 25 & 279 & \\
\hline Not evaluated & 4 & 18 & \\
\hline Total & 217 & 3954 & \\
\hline
\end{tabular}

$P L C$, Pleural lavage cytology.

$\mathrm{N}$, and $\mathrm{M}$ categories and by pathologic stages, significantly higher percentages of advanced cases were seen among patients with positive PLC results compared with patients with negative PLC results. Patients with positive PLC results also had significantly larger tumors than those who were PLC-negative. A significantly higher percentage of

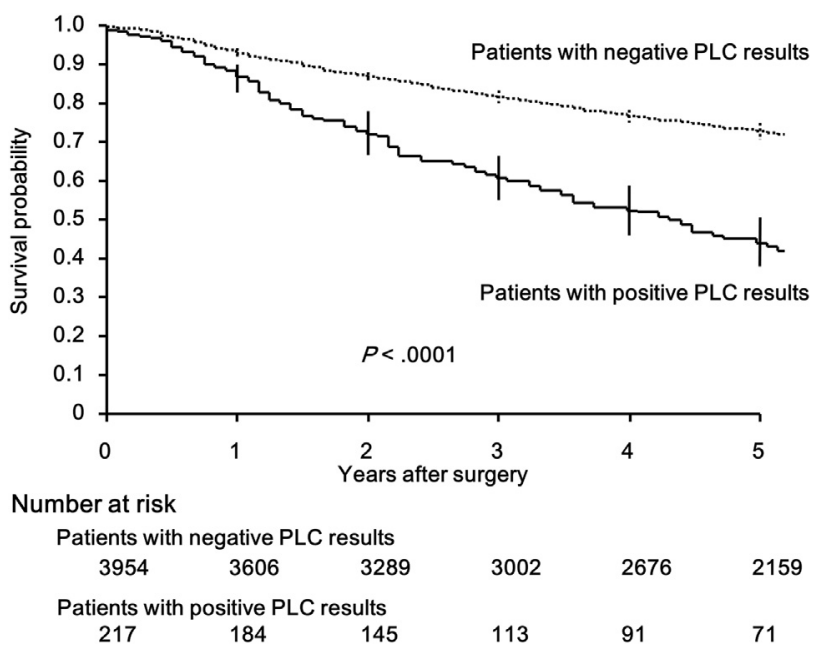

FIGURE 1. Postoperative survival curves based on pleural lavage cytology $(P L C)$ status. There was a significant difference between patients with positive and negative PLC results $(P<.0001)$. The solid line indicates patients with positive PLC results and the dashed line indicates patients with negative PLC results. The vertical bars indicate $95 \%$ confidence intervals.

pleural invasion was evident among patients with positive PLC results compared with those who were PLCnegative. These characteristics are consistent with those described in previous reports. ${ }^{1,9,10,12,14,19}$ In our study, the 5-year survival was $44.5 \%$ for patients with positive PLC results and $72.8 \%$ for patients with negative PLC results, which indicated a significantly worse prognosis for patients with positive PLC results. A multivariate analysis revealed that PLC finding is an independent prognostic

TABLE 2. Multivariate analysis for prognostic factors

\begin{tabular}{lccc}
\hline Prognostic factor & Hazard ratio & $\mathbf{9 5} \%$ Confidence interval & $\boldsymbol{P}$ value \\
\hline Positive PLC & 1.57 & $1.276-1.919$ & $<.0001$ \\
Male gender & 1.66 & $1.460-1.894$ & $<.0001$ \\
Age, per year & 1.03 & $1.023-1.036$ & $<.0001$ \\
T category & & & \\
T1a & 1.00 & - & - \\
T1b & 1.59 & $1.266-1.990$ & $<.0001$ \\
T2a & 2.01 & $1.645-2.461$ & $<.0001$ \\
T2b & 2.79 & $2.048-3.794$ & $<.0001$ \\
T3 & 2.94 & $2.271-3.807$ & $<.0001$ \\
T4 & 3.87 & $2.692-5.564$ & $<.0001$ \\
N category & & & \\
N0 & 1.00 & - & - \\
N1 & 1.76 & $1.459-2.111$ & $<.0001$ \\
N2 & 3.13 & $2.735-3.580$ & $<.0001$ \\
N3 & 9.27 & $5.083-16.913$ & $<.0001$ \\
M category & & & \\
M0 & 1.00 & - & - \\
M1a & 1.89 & $1.349-2.643$ & $<.0001$ \\
M1b & 4.02 & $2.601-6.206$ & $<.0001$ \\
Tumor size (cm) & 1.05 & $1.014-1.085$ & .006 \\
\hline$P L C$ P & & &
\end{tabular}

$P L C$, Pleural lavage cytology. 

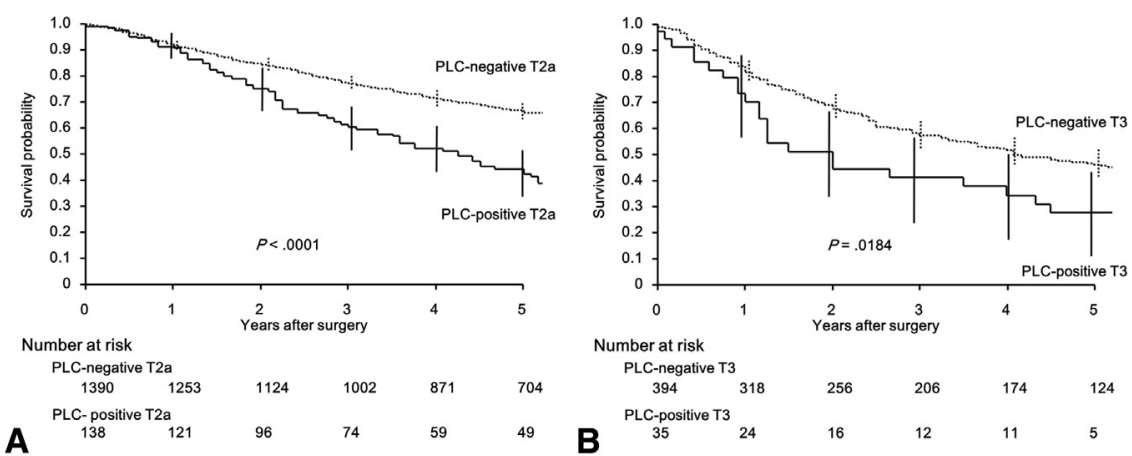

FIGURE 2. Comparisons of survival curves between patients with positive and negative pleural lavage cytology $(P L C)$ results based on T categories. A, There was a significant difference between PLC-positive T2a and PLC-negative T2a $(P<.0001)$. B, There was a significant difference between PLC-positive T3 and PLC-negative T3 $(P=.2261)$. Solid lines indicate patients with positive PLC results and dashed lines indicate patients with negative PLC results. The vertical bars indicate $95 \%$ confidence intervals.

factor with a hazard ratio of 1.57. PLC status has been suggested to be an independent prognostic factor in previous reports. $6,12,14,16,19,21$ Some reports only recognized certain stages as an independent factor and other reports stated that PLC status was not an independent prognostic factor. ${ }^{17,18}$ Recent studies that used meta-analyses have shown that PLC status is an independent prognostic factor. ${ }^{23,24,26}$ However the time periods considered in these studies covered a wide range. In our study, patients were limited to those who underwent surgery during 2004; thus, patients were evaluated and treated according to a relatively standardized procedure.

The prognoses for patients with positive and negative PLC results were compared by $\mathrm{T}$ category and pathologic

TABLE 3. Comparisons of survival rates between patients with positive and negative pleural lavage cytology (PLC), according to $T$ categories and pathologic stages

\begin{tabular}{|c|c|c|c|c|c|}
\hline \multirow[b]{2}{*}{ Category or stage } & \multicolumn{2}{|c|}{ Positive PLC } & \multicolumn{2}{|c|}{ Negative PLC } & \multirow[b]{2}{*}{$P$ value } \\
\hline & $\mathbf{n}$ & $\begin{array}{c}5-y \\
\text { survival (\%) }\end{array}$ & $\mathbf{n}$ & $\begin{array}{c}5-y \\
\text { survival (\%) }\end{array}$ & \\
\hline \multicolumn{6}{|l|}{$\mathrm{T}$ category } \\
\hline T1a & 14 & 76.2 & 1147 & 88.3 & .2977 \\
\hline T1b & 12 & 71.3 & 771 & 79.2 & .1951 \\
\hline $\mathrm{T} 2 \mathrm{a}$ & 138 & 45.1 & 1390 & 67.7 & $<.0001$ \\
\hline $\mathrm{T} 2 \mathrm{~b}$ & 9 & 25.0 & 186 & 53.7 & .1100 \\
\hline $\mathrm{T} 3$ & 35 & 27.7 & 394 & 46.4 & .0184 \\
\hline $\mathrm{T} 4$ & 9 & 19.4 & 66 & 36.2 & .9587 \\
\hline \multicolumn{6}{|l|}{ Pathologic stage } \\
\hline IA & 15 & 100 & 1679 & 88.8 & - \\
\hline IB & 60 & 61.5 & 949 & 77.1 & .0062 \\
\hline IIA & 23 & 48.3 & 355 & 62.9 & .0833 \\
\hline IIB & 12 & 37.0 & 250 & 51.8 & .5496 \\
\hline IIIA & 74 & 26.4 & 629 & 42.5 & .0115 \\
\hline IIIB & 4 & 37.5 & 34 & 20.2 & .2912 \\
\hline IV & 29 & 27.8 & 58 & 30.3 & .4962 \\
\hline Total & 217 & 44.5 & 3954 & 72.8 & $<.0001$ \\
\hline
\end{tabular}

PLC, Pleural lavage cytology. stage based on the seventh edition of the UICC TNM classification. Significant differences in survival were found between the patients with positive and negative PLC results within the same T category and stage, including T2a, T3, stage IB, and stage IIIA. One reason for these findings may be differences in the number of patients in each group. For example, the T2a and T3 stages included more patients than the other T subclassifications. Similarly, the stage IB and stage IIIA categories included more patients than the other subgroups. Based on the sixth edition of the UICC TNM classification, the IPLCC recommended that a single increase in the $\mathrm{T}$ category up to a maximum of $\mathrm{T} 4$ be assigned to those with positive PLC results. ${ }^{24}$ We performed a single increase in the $\mathrm{T}$ category based on the seventh edition of the TNM classification. The significant differences in the survival between patients with positive and negative PLC results disappeared for all $\mathrm{T}$ categories and stages.

The significance of incorporating PLC findings into the TNM classification system is reflected in the treatments for upstaged patients, such as the addition of adjuvant therapy or a change to a more effective adjuvant therapy. There have been some proposals for incorporating PLC findings in the TNM classification system in which patients with positive PLC results were classified into T3 disease, ${ }^{25}$ T4 disease, ${ }^{9,21}$ or stage IIIB disease. ${ }^{14}$ However there was no consensus among these proposals because most of these series were too small for detailed analysis. Moreover, because PLC status is related to multiple prognostic factors, it may be inappropriate for patients with positive PLC results to be classified into a single $\mathrm{T}$ category or single stage. The IPLCC recommendation should be the most reliable proposal because it is based on an exploratory statistical model using data from a multiinstitution study.

This study is associated with several limitations that should be considered when interpreting the results. First, the PLC technique has not been standardized. The IPLCC recommends that $100 \mathrm{~mL}$ saline be irrigated over the lung 

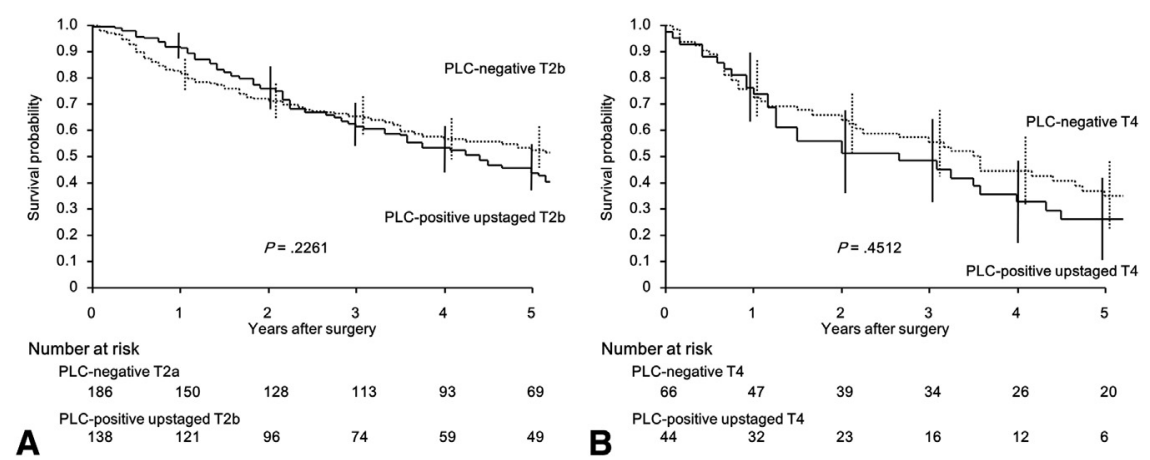

FIGURE 3. Comparisons of survival curves between patients with positive and negative pleural lavage cytology $(P L C)$ results according to reevaluations based on International Pleural Lavage Cytology Collaborators recommendations. A, There was no significant difference between PLC-positive upstaged T3 and PLC-negative T3. B, There was no significant difference between PLC-positive upstaged T4 and PLC-negative T4. Solid lines indicate patients with positive PLC results and dashed lines indicate patients with negative PLC results. The vertical bars indicate $95 \%$ confidence intervals.

surface immediately after thoracotomy and before lung resection, after which the saline is aspirated and a sample is sent for cytologic screening for malignant cells. ${ }^{24}$ In addition, patients with positive PLC results after pulmonary resection have a worse prognosis than those with positive PLC results immediately after thoracotomy. ${ }^{16,20,21}$ The finding of a positive PLC result after pulmonary resection is thought to involve human factors associated with surgical manipulation, ${ }^{11}$ and the PLC results obtained immediately after thoracotomy may more accurately reflect the biologic malignancy of lung cancer. Second, only $37.3 \%$ of NSCLC patients had PLC in this study. One reason for this finding is that the value of PLC has not been recognized in many institutions. In our study, patients who underwent PLC were not compared with the excluded

TABLE 4. Comparisons of survival rates between patients with positive and negative pleural lavage cytology (PLC), according to upstaged $\mathrm{T}$ categories and reevaluated pathologic stages

\begin{tabular}{|c|c|c|c|c|c|}
\hline \multirow[b]{2}{*}{ Category or stage } & \multicolumn{2}{|c|}{ Positive PLC } & \multicolumn{2}{|c|}{ Negative PLC } & \multirow[b]{2}{*}{$P$ value } \\
\hline & $\mathbf{n}$ & $\begin{array}{c}5-y \\
\text { survival }(\%)\end{array}$ & $\mathbf{n}$ & $\begin{array}{c}5-y \\
\text { survival }(\%)\end{array}$ & \\
\hline \multicolumn{6}{|l|}{ Upstaged T category } \\
\hline T1a & - & - & 1147 & 88.3 & - \\
\hline $\mathrm{T} 1 \mathrm{~b}$ & 14 & 76.2 & 771 & 79.2 & .9417 \\
\hline $\mathrm{T} 2 \mathrm{a}$ & 12 & 71.3 & 1390 & 67.7 & .7518 \\
\hline $\mathrm{T} 2 \mathrm{~b}$ & 138 & 45.1 & 186 & 53.7 & .2261 \\
\hline $\mathrm{T} 3$ & 9 & 25.0 & 394 & 46.4 & .2568 \\
\hline $\mathrm{T} 4$ & 44 & 27.6 & 66 & 36.2 & .4512 \\
\hline \multicolumn{6}{|c|}{ Reevaluated pathologic stage } \\
\hline IA & 8 & 100 & 1679 & 88.8 & - \\
\hline IB & 7 & 100 & 949 & 77.1 & - \\
\hline IIA & 62 & 61.2 & 355 & 62.9 & .8223 \\
\hline IIB & 21 & 48.0 & 250 & 51.8 & .6953 \\
\hline IIIA & 70 & 29.6 & 629 & 42.5 & .1234 \\
\hline IIIB & 20 & 23.6 & 34 & 20.2 & .8662 \\
\hline IV & 29 & 27.8 & 58 & 30.3 & .4962 \\
\hline Total & 217 & 44.5 & 3954 & 72.8 & $<.0001$ \\
\hline
\end{tabular}

$P L C$, Pleural lavage cytology. patients. However, $94.8 \%$ of patients who underwent PLC were PLC-negative, with clinicopathologic characteristics similar to those of general NSCLC patients. Third, the patients with positive PLC results were significantly different from those with negative PLC results. Matching may equalize this inequality and permit true exploration of the effects of PLC in similar patients. However, we did not match the patients because the aim of our study was to retrospectively examine the clinical significance of the PLC status and illustrate the recommendations of the IPLCC based on an exploratory statistical model using data obtained from a multiinstitution study. ${ }^{24}$ Fourth, we did not investigate the incidence of pleural recurrence, although PLC-positive patients had more episodes of recurrence than PLC-negative patients within 5 years after surgery. Patients with positive PLC results have been reported to have a high incidence of pleural recurrence. ${ }^{19,25,26,33}$ Other reports have indicated that local intrapleural therapy is effective for local control, although this treatment does not improve survival. ${ }^{18,34}$ Because the PLC findings affect all $\mathrm{T}, \mathrm{N}$, and $\mathrm{M}$ categories, the administration of systemic adjuvant chemotherapy may be effective in patients with positive PLC results. The importance of incorporating PLC results into the TNM classification will be recognized only if the effectiveness of adjuvant chemotherapy is demonstrated prospectively in patients with positive PLC results.

\section{CONCLUSIONS}

PLC status was an independent prognostic factor in patients with NSCLC who had been surgically treated. Based on the recommendations of the IPLCC, if a single increase in the $\mathrm{T}$ category up to a maximum of $\mathrm{T} 4$ is assigned to a patient with a positive PLC result, the significant difference in survival disappears between the 2 groups in all $\mathrm{T}$ categories and stages. This recommendation appears to be an appropriate method for incorporating PLC findings into the seventh edition of the UICC TNM 
classification. The implications of incorporating PLC findings into the TNM classification system is reflected in the treatments for upstaged patients, such as the addition of adjuvant therapy or a change to a more effective adjuvant therapy.

We hope that PLC findings will be incorporated in the next revision of the UICC TNM classification.

\section{References}

1. Eagan RT, Bernatz PE, Payne WS, Pairolero PC, Williams DE, Goellner JR, et al. Pleural lavage after pulmonary resection for bronchogenic carcinoma. J Thorac Cardiovasc Surg. 1984:88:1000-3.

2. Kondo H, Naruke T, Tsuchiya R, Goya T, Suemasu K, Yamagishi K, et al. Pleural lavage cytology immediately after thoracotomy as a prognostic factor for patients with lung cancer. Jpn J Cancer Res. 1989;80:233-7.

3. Buhr J, Berghauser KH, Morr H, Dobroschke J, Ebner HJ. Tumor cells in intraoperative pleural lavage. An indicator for the poor prognosis of bronchogenic carcinoma. Cancer. 1990;65:1801-4.

4. Okumura M, Ohshima S, Kotake Y, Morino H, Kikui M, Yasumitsu T. Intraoperative pleural lavage cytology in lung cancer patients. Ann Thorac Surg. 1991;51:599-604.

5. Kondo H, Asamura H, Suemasu K, Goya T, Tsuchiya R, Naruke T, et al. Prognostic significance of pleural lavage cytology immediately after thoracotomy in patients with lung cancer. J Thorac Cardiovasc Surg. 1993; 106:1092-7.

6. Buhr J, Berghauser KH, Gonner S, Kelm C, Burkhardt EA, Padberg WM. The prognostic significance of tumor cell detection in intraoperative pleural lavage and lung tissue cultures for patients with lung cancer. $J$ Thorac Cardiovasc Surg. 1997;113:683-90.

7. Higashiyama M, Doi O, Kodama K, Yokouchi H, Tateishi R, Horai T, et al. Pleural lavage cytology immediately after thoracotomy and before closure of the thoracic cavity for lung cancer without pleural effusion and dissemination: clinicopathologic and prognostic analysis. Ann Surg Oncol. 1997;4:409-15.

8. Dresler CM, Fratelli C, Babb J. Prognostic value of positive pleural lavage in patients with lung cancer resection. Ann Thorac Surg. 1999;67:1435-9.

9. Okada M, Tsubota N, Yoshimura M, Miyamoto Y, Maniwa Y. Role of pleural lavage cytology before resection for primary lung carcinoma. Ann Surg. 1999; 229:579-84.

10. Ichinose Y, Tsuchiya R, Yasumitsu T, Koike T, Yamato Y, Nakagawa K, et al. Prognosis of non-small cell lung cancer patients with positive pleural lavage cytology after a thoracotomy: results of the survey conducted by the Japan Clinical Oncology Group. Lung Cancer. 2001;31:37-41.

11. Kotoulas C, Lazopoulos G, Karaiskos T, Tomos P, Konstantinou M, Papamichalis G, et al. Prognostic significance of pleural lavage cytology after resection for non-small cell lung cancer. Eur J Cardiothorac Surg. 2001;20: 330-4.

12. Okada M, Sakamoto T, Nishio W, Uchino K, Tsuboshima K, Tsubota N. Pleural lavage cytology in non-small cell lung cancer: lessons from 1000 consecutive resections. J Thorac Cardiovasc Surg. 2003;126:1911-5.

13. Riquet M, Badoual C, Le Pimpec Barthes F, Lhote FM, Souilamas R, Hubsch JP, et al. Visceral pleura invasion and pleural lavage tumor cytology by lung cancer: a prospective appraisal. Ann Thorac Surg. 2003;75:353-5.

14. Lim E, Ali A, Theodorou P, Nicholson AG, Ladas G, Goldstraw P. Intraoperative pleural lavage cytology is an independent prognostic indicator for staging non-small cell lung cancer. J Thorac Cardiovasc Surg. 2004;127:1113-8.

15. Vicidomini G, Santini M, Fiorello A, Parascandolo V, Calabro B, Pastore V. Intraoperative pleural lavage: is it a valid prognostic factor in lung cancer? Ann Thorac Surg. 2005;79:254-7.

16. Enatsu S, Yoshida J, Yokose T, Nishimura M, Nishiwaki Y, Shirakusa T, et al. Pleural lavage cytology before and after lung resection in non-small cell lung cancer patients. Ann Thorac Surg. 2006;81:298-304.
17. Nakagawa T, Okumura N, Kokado Y, Miyoshi K, Matsuoka T, Kameyama K. Clinical relevance of intraoperative pleural lavage cytology in non-small cell lung cancer. Ann Thorac Surg. 2007;83:204-8.

18. Satoh Y, Hoshi R, Ishikawa Y, Horai T, Okumura S, Nakagawa K. Recurrence patterns in patients with early stage non-small cell lung cancers undergoing positive pleural lavage cytology. Ann Thorac Surg. 2007;83: 197-202.

19. Higashiyama M, Oda K, Okami J, Maeda J, Kodama K, Takenaka A, et al. Prognostic value of intraoperative pleural lavage cytology for lung cancer without carcinomatous pleuritis: importance in patients with early stage disease during long-term follow-up. Eur J Cardiothorac Surg. 2009;35:337-42.

20. Shintani Y, Ohta M, Iwasaki T, Ikeda N, Kanou T, Tomita E, et al. Intraoperative pleural lavage cytology after lung resection as an independent prognostic factor for staging lung cancer. J Thorac Cardiovasc Surg. 2009;137:835-9.

21. Aokage K, Yoshida J, Ishii G, Enatsu S, Hishida T, Nishimura M, et al. The impact on survival of positive intraoperative pleural lavage cytology in patients with non-small-cell lung cancer. J Thorac Cardiovasc Surg. 2010;139: 1246-52.

22. Mordant P, Rivera C, Legras A, Le Pimpec Barthes F, Riquet M. Current readings: the most influential and recent studies regarding resection of lung cancer in M1a disease. Semin Thorac Cardiovasc Surg. 2013;25:251-5.

23. Li YN, Shi HZ, Liang QL, Yang HB, Huang GM. Prognostic significance of pleural lavage cytology in patients with lung cancer: a meta-analysis. Lung Cancer. 2008;60:183-92.

24. Lim E, Clough R, Goldstraw P, Edmonds L, Aokage K, Yoshida J, et al. Impact of positive pleural lavage cytology on survival in patients having lung resection for non-small-cell lung cancer: An international individual patient data meta-analysis. J Thorac Cardiovasc Surg. 2010;139:1441-6.

25. Kaneda M, Yokoi K, Ito S, Niwa H, Takao M, Kondo R, et al. The value of pleural lavage cytology examined during surgery for primary lung cancer. Eur J Cardiothorac Surg. 2012;41:1335-41.

26. Saso S, Rao C, Ashrafian H, Ghaem-Maghami S, Darzi A, Athanasiou T. Positive pre-resection pleural lavage cytology is associated with increased risk of lung cancer recurrence in patients undergoing surgical resection: a meta-analysis of 4450 patients. Thorax. 2012;67:526-32.

27. Goldstraw P, International Association for the Study of Lung Cancer. Staging manual in thoracic oncology. Orange Park, FL: Editorial Rx Press; 2009.

28. Sobin LH, Gospodarowicz MK, Wittekind C; International Union against Cancer. TNM classification of malignant tumours. 7th ed. Hoboken, NJ: Wiley-Blackwell; 2010.

29. Sawabata N, Asamura H, Goya T, Mori M, Nakanishi Y, Eguchi K, et al. Japanese Lung Cancer Registry Study: first prospective enrollment of a large number of surgical and nonsurgical cases in 2002. J Thorac Oncol. 2010;5:1369-75.

30. Sawabata N, Miyaoka E, Asamura H, Nakanishi Y, Eguchi K, Mori M, et al. Japanese lung cancer registry study of 11,663 surgical cases in 2004: demographic and prognosis changes over decade. J Thorac Oncol. 2011;6: 1229-35.

31. Hermanek P, Hutter RV, Sobin LH, Wittekind C. International Union Against Cancer. Classification of isolated tumor cells and micrometastasis. Cancer. 1999;86:2668-73

32. Goldstraw P, Crowley J, Chansky K, Giroux DJ, Groome PA, Rami-Porta R, et al. The IASLC Lung Cancer Staging Project: proposals for the revision of the TNM stage groupings in the forthcoming (seventh) edition of the TNM Classification of malignant tumours. J Thorac Oncol. 2007;2:706-14.

33. Higashiyama M, Kodama K, Yokouchi H, Takami K, Nakayama T, Horai T. Clinical value of pleural lavage cytological positivity in lung cancer patients without intraoperative malignant pleuritis. Recurrent pattern based on semiquantitative analysis of tumor cells in pleural lavage. Jpn J Thorac Cardiovasc Surg. 2000;48:611-7.

34. Ichinose Y, Tsuchiya R, Koike T, Yasumitsu T, Nakamura K, Tada H, et al. A prematurely terminated phase III trial of intraoperative intrapleural hypotonic cisplatin treatment in patients with resected non-small cell lung cancer with positive pleural lavage cytology: the incidence of carcinomatous pleuritis after surgical intervention. J Thorac Cardiovasc Surg. 2002;123:695-9. 